\section{EFICÁCIA DA FONOFORESE COM XIMENIA AMERICANA L. NA INFLAMAÇÃO DE TENDÃO DE RATOS}

\author{
PHONOPHORESIS EFFECTIVENESS WITH XIMENIA AMERICANA L. IN RATS TENDON INFLAMMATION \\ EFICACIA DE LA FONOFORESIS CON XIMENIA AMERICANA L. EN LA INFLAMACIÓN \\ DETENDÓN DERATAS
}

\section{RESUMO}

Introdução: Diversos recursos terapêuticos, como laser e ultrassom isolado, combinados com fármacos e fonoforese têm sido utilizados em casos de inflamaação e reparo de tendão, sendo o ultrassom pulsado bastante eficaz em tendinites crônicas. Objetivo: Analisar a eficácia do uso da fonoforese com o extrato etanólico das cascas do caule da Ximenia americana L. na resolução do processo inflamatório crônico em Rattus norvegicus. Métodos: A amostra consistiu em 120 animais para análise da resposta inflamatória, utilizando-se como variáveis edema, força biomecânica, número de fibroblastos e análise histológica. Resultados: Nos $7^{\circ}$ e no $14^{\circ}$ dia, verificou-se diferença significativa entre o grupo ultrassom com gel do caule de Ximenia americana $L$. e o grupo ultrassom com placebo $(p<0,05)$ quanto à redução de edema, aumento da força máxima de ruptura, redução extremamente significativa da deformação máxima $(p<0,001)$, além de aumento dos fibroblastos. Na análise histológica, houve melhora do processo inflamatório inicial e aceleração do reparo tendíneo, com redução de células inflamatórias e com deposição de colágeno organizado com matriz extracelular densa. Conclusão: O ultrassom pulsado combinado com o gel do caule de Ximenia americana L. é uma forma terapêutica eficaz para a resolução do processo inflamatório crônico.

Descritores: fonoforese; olacaceae; inflamação; tendão do calcâneo.

\section{ABSTRACT}

Introduction: Several therapeutic resources such as laser and isolated ultrasound combined with drugs and phonophoresis have been used in cases of inflammation and tendon repair, and the pulsed ultrasound is quite effective in chronic tendinitis. Objective: To analyze the efficacy of phonophoresis with the ethanol extract of the stem bark of Ximenia americana L. to manage the chronic inflammatory process in Rattus norvegicus. Methods: The sample consisted of 120 animals for analysis of the inflammatory response using edema, biomechanical strength, number of fibroblasts and histological analysis as variables. Results: On the $7^{\text {th }}$ and $14^{\text {th }}$ day, there was a significant difference between the group ultrasound with Ximenia americana L. gel and the ultrasound with placebo group $(p<0.05)$ for edema reduction, increased maximum rupture strength, highly significant reduction of the maximum deformation $(p<0.001)$, in addition to an increase in fibroblasts. In the histological analysis, there was improvement in the inflammatory process and acceleration of tendon repair with reduction of inflammatory cells and deposition of organized collagen with dense extracellular matrix. Conclusion: The pulsed ultrasound combined with gel of Ximenia americana L. is an effective therapy to manage the chronic inflammatory process.

Keywords: phonophoresis; olacaceae; inflammation; achilles tendon.

\section{RESUMEN}

Introducción: Varios recursos terapéuticos, tales como láser y ultrasonido aislado, en combinación con fármacos y la fonoforesis se han utilizado en casos de inflamación y reparación del tendón, y el ultrasonido pulsado ha sido muy eficaz en la tendinitis crónica. Objetivo: Analizar la eficacia de la fonoforesis con el extracto de etanol de la corteza del tallo de Ximenia americana L. en la resolución del proceso inflamatorio crónico en Rattus norvegicus. Métodos: La muestra fue de 120 animales para analizar la respuesta inflamatoria, utilizando como variables el edema, la resistencia biomecánica, el número de fibroblastos y el análisis histológico. Resultados: En el $7^{\circ}$ y en el $14^{\circ}$ día, se observó una diferencia significativa entre el grupo de ultrasonido con gel de Ximenia americana L. y el grupo ultrasonido con placebo $(p<0,05)$ en la reducción del edema, el aumento de la resistencia máxima a la rotura, la reducción altamente significativa de la deformación máxima $(p<0,001)$, además del aumento de los fibroblastos. En el análisis histológico hubo una mejoría en el proceso inflamatorio y la aceleración de la reparación del tendón, con reducción de células inflamatorias y deposición de colágeno organizado con matriz extracelular densa. Conclusión: La eficacia del ultrasonido pulsado combinado con gel de Ximenia americana L. es una forma eficaz para la resolución del proceso inflamatorio crónico.

Descriptores: fonoforesis; olacaceae; inflamación; tendón calcáneo. 


\section{INTRODUÇÃO}

As lesões e outras desordens do tendão representam um desafio comum para o diagnóstico e terapêutica na medicina, resultando em inflamações de longa duração. A degeneração do tendão é um achado comum em muitas queixas relacionadas com o desporto 1,2.

O papel do processo inflamatório, as modificações histopatológicas e a patogênese da lesão crônica do tendão não estão completamente entendidos. Sabe-se que quando o tendão é posto em sobrecarga ele perde a sua capacidade reparadora basal podendo levar à micro traumas cumulativos que enfraquecem as ligações do colágeno, a matriz nãocolágena e os elementos vasculares do tendão ${ }^{3}$.

Diversos recursos terapêuticos como Laser ${ }^{4,5}$, Led e ultrassom tera-

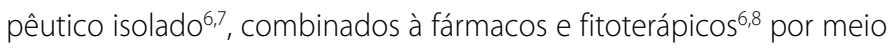
da sonoforese tem sido utilizados na inflamação e reparo de tendão.

Compostos com atividade anti-inflamatória extraídos de plantas da medicina popular, avaliados em modelos experimentais, mostram que novas drogas direta ou indiretamente derivadas dos produtos naturais podem ser usadas para o tratamento da inflamação9,10.

A cultura popular brasileira é particularmente rica no uso das plantas medicinais uma delas é a Ximenia americana L. ${ }^{11}$, todas as partes desta planta têm indicações de uso na medicina popular ${ }^{12}$. 0 caule pulverizado é recomendado para cicatrização, anti-inflamatório, perturbação gástrica ${ }^{13}$.

O objetivo deste estudo é avaliar a eficácia terapêutica do gel das cascas do caule da X. americana, através da sonoforese na redução do processo inflamatório e reparo tecidual.

\section{MATERIAL E MÉTODOS}

Foram utilizados 120 animais (Rattus norvegicus, machos, Wistar, 300g), divididos em seis grupos, agrupados por período de acordo com o tratamento e a análise dos dados histológicos, que seguiram um padrão de 7 e 14 dias $^{8}$. Mantidos em laboratório climatizado, com ração balanceada para todos, livres de odores, com luminosidade, temperatura ideal e isento de microrganismos patogênicos, com idade acima de 30 dias, em um ciclo de claro e escuro de 12 horas com alimentação e água "ad libitum". No final da pesquisa os ratos foram sacrificados com uma superdosagem do anestésico tiopental a $2 \%$. O protocolo de pesquisa foi submetido à análise e aprovado com o protocolo 254/09 e registro n 655/2009, folha 014 em 02/10/09 pelo Comitê de Ética em Pesquisa Faculdade Integral Diferencial (CEP/FACID), localizado em TeresinaPiauí- Brasil e registrado junto ao SISNEP. Os grupos da pesquisa estão relacionados no Quadro 1.

\section{Indução do processo inflamatório}

Os ratos foram anestesiados com cetamina $(100 \mathrm{mg} / \mathrm{kg})$ e xilazina $(20 \mathrm{mg} / \mathrm{kg}$ ) e posteriormente receberam a injeção intratendínea de $10 \mu$ l de colagenase (10 mg/ml:SIGMA: C6885). A colagenase foi diluída em solução salina estéril de fosfato e injetada no tendão de Aquiles ${ }^{14}$.

\section{Preparação do extrato e gel casca do caule da Ximenia americana $L$.}

As cascas do caule da X. americana L., usadas na fabricação do gel foram coletadas no município de Campo Maior, PI, Brasil. Uma exsicata encontra-se depositada no Herbário da Universidade Federal do Piauí, sob o número TEBP 14407. As cascas do caule $(3,3 \mathrm{~kg})$ foram secas a temperatura ambiente $\left(32 \pm 1^{\circ} \mathrm{C}\right)$, trituradas e extraída com etanol $95 \%$. O extrato etanólico (620g), foi obtido na Universidade Estadual do Piauí. Pesou-se 2,5 g do extrato e solubilizou em $20 \mathrm{ml}$ da mistura dos solventes etanol/água na proporção 3:7 e adicionou a solução de $500 \mathrm{~g}$ do gel de carbopol e obtivemos o gel de carbopol com extrato a 5\%.

\section{Protocolo de aplicação do ultrassom}

Nesta pesquisa foi usado o ultrassom IBRAMED (Indústria Brasileira de Equipamentos Médicos EIRELI, ANVISA no 10360310025; Amparo - SP - Brasil ),com seguintes parâmetros: modo pulsado a $10 \%$, frequência de $100 \mathrm{~Hz}$, intensidade de $0,5 \mathrm{~W} / \mathrm{cm}^{2}$, método direto de acoplamento, com movimentos oscilatórios constantes, numa ERA de $1 \mathrm{~cm}^{2}$, durante 120 segundos com um equipamento devidamente calibrado ${ }^{8}$. Dois tipos de géis foram utilizados nesse experimento: gel de carbopol (100\%) e gel do extrato a 5\%.

\section{Análises das respostas inflamatórias}

O edema da pata foi medido pelo paquímetro. As leituras foram realizadas diariamente por um período de 14 dias. Todos os tratamentos e leituras foram realizados na pata traseira direita de cada animal. Para a intervenção e manuseio os animais foram anestesiados ${ }^{8}$.

Para a análise de força tensil, o tendão de Aquiles foi retirado e colocado em recipientes com solução de ringer lactato e encaminhados para o teste de resistência à tensão, por meio da Máquina de Ensaio Universal DL20000, com garras de pressão ajustáveis manualmente e sistema eletrônico de aquisição de dados com utilização do software Tesc, versão 1.01 (Emic ${ }^{\circledR}$, São José dos Pinhais, PR, BR). O tendão sofreu pinçamento através de um dispositivo de aço inoxidável com pressão gradual, criado para tração do tendão e com ranhuras na sua superfície interna para preensão firme das margens distal e proximal observandose a força de ruptura (FR) e a deformação máxima (DM) ${ }^{8}$.

\section{Preparo das lâminas e análise histológica}

O tecido foi fixado em formol $10 \%$ por um período de $24 \mathrm{~h}$, em seguida a peça foi desidratada em etanol com porcentagens crescentes $(50 \%, 70 \%, 80 \%, 90 \%)$ por períodos de 1 h e em etanol a $100 \%$ durante 8h. Após a desidratação a peça foi diafanizada em xilol por 4h, permanecendo em parafina por 4 h em estufa a $58^{\circ} \mathrm{C}$, sendo emblocada para a realização dos cortes histológicos ${ }^{14}$.

A preparação foi realizada no laboratório de Patologia do Centro de Ciências da Saúde da Universidade Estadual do Piauí. As peças coradas com hematoxilina eosina - H.E. e com tricrômio de Masson (Sigma-Aldrich, №117K4340) foram examinadas com um microscópio óptico trinolucular Olympus CX31, modelo YS100, equipado com câmera digital Olympus SC20 (Blue Lagoon Drive, Miami - U.S.A) e acoplado a um microcomputador. As lâminas coradas com HE observaram-se as seguintes características: arranjo das fibras de colágeno; neovascularização e tipo de reação inflamatória e tipo de célula predominante: agudo (neutrófilos), crônico (linfócitos) e agudo-crônico (sem predominância de neutrófilos ou linfócitos) e as com tricrômio de Masson foram submetidas à analise morfológica de colágeno ${ }^{14}$.

A avaliação histomorfométrica foi realizada nas lâminas coradas com o tricrômico de Masson, sendo quantificado o número de fibroblastos. Sob aumento de 100 e 400 vezes, capturaram-se de cada lâmina dois campos microscópicos em que havia maior concentração celular. As imagens digitalizadas foram então analisadas com auxílio do programa de análise computacional de imagens Image-- ${ }^{\circledR}$ (Versão 1,32 para Windows) de domínio público (http://rsb.info.nih.gov/ij/download.html), do Instituto Nacional de Saúde (NIH), Bethesda, EUA. Os dados foram apresentados como média e desvio-padrão (média \pm DP).

\section{Análise estatística}

A análise estatística foi realizada utilizando o programa estatístico GraphPad Prism $5^{\circledR}$ (GraphPad Software, Inc. La Jolla, CA 92037 USA) para análises de one way ANOVA (não paramétrico) e Teste de Tukey, com nível de significância de 5\% $(p<0,05)$. 


\section{RESULTADOS}

Em sete dias (Figura 1a) e 14 dias (Figura 1b), após a indução da tendinite em cada grupo de animais utilizados no experimento houve uma redução muito significativa do edema entre o grupo ultrassom com gel do caule (USGCA) e os outros grupos (placebo e grupo ultrassom com gel comum (USGC)).

Em sete dias de tratamento (Figura 2a) e 14 dias (Figura 2b) em relação intergrupos demonstrou que houve diferença significativa no incremento da força de ruptura (FR), entre o grupo ultrassom com gel do caule (USGCA) e os demais (gel tópico do caule (GTCA), placebo e ultrassom com gel comum (USGC)).

Em sete dias de tratamento (Figura 3a), as interrelações entre os grupos tratados mostraram diferenças significativas entre os grupos: ultrassom com gel comum (USGC), ultrassom com gel do caule (USGCA) e placebo. A deformação em 14 dias (Figura 3b), na avaliação de intergrupos mostrou que não houve diferença estatisticamente significativa entre os grupos tratados.

O número de fibroblastos avaliado pela histomorfometria mostrou uma diferença estatisticamente significativa, aos sete dias de tratamento (Figura 4a) e 14 dias (Figura 4b), entre os grupos de tratamento ultrassom com gel comum (USGC), placebo, gel tópico do caule (GTCA) e ultrassom com gel do caule (USGCA).

Tabela 1. Divisão dos animais em grupos e terapias utilizadas na pesquisa.

\begin{tabular}{|c|c|}
\hline Grupos & Terapia \\
\hline $\begin{array}{c}\text { GRUPO } 1 \text { (USGC) } \\
\text { Ultrassom com Gel Comum. }\end{array}$ & Inflamação + ultrassom terapêutico. \\
\hline $\begin{array}{c}\text { GRUPO } 2 \text { (GTCA) } \\
\text { Gel Tópico do Caule }\end{array}$ & $\begin{array}{c}\text { Inflamação + aplicação tópica do gel } \\
\text { do caule (5\%) da X. americana. }\end{array}$ \\
\hline $\begin{array}{c}\text { GRUPO } 3 \text { (USGCA) } \\
\text { Ultrassom com Gel do Caule }\end{array}$ & $\begin{array}{l}\text { Inflamação + sonoforese com gel do } \\
\text { caule (5\%) da X. americana. }\end{array}$ \\
\hline GRUPO 4 (PLACEBO) & U.S cabeçote desligado + gel comum. \\
\hline
\end{tabular}
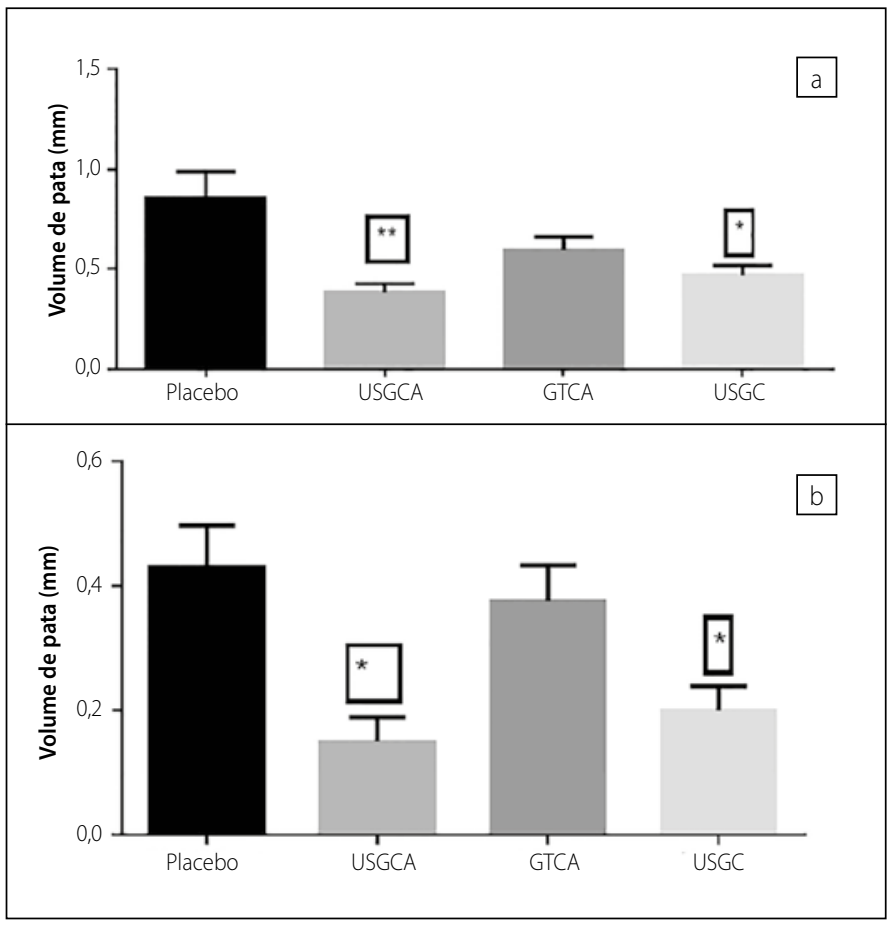

Figura 1. USGCA (Ultrassom com gel do caule); GTCA (Gel tópico do caule); USGC (Ultrassom com gel comum). a) Volume do edema após a indução da inflamação com colagenase no tendão do rato; b) Grupos de animais eutanasiados em sete e quatorze dias respectivamente. Valores expressos em média \pm desvio padrão.

\section{Análise histológica}

Em sete dias (Figura 5), as análises histológicas em laminas coradas com hematoxilina-eosina (HE) e tricrômico de Masson (TM) mostraram no grupo Placebo (Figura 5A e 5B), no epitendão, número moderado de fibroblastos e de pequenos vasos sanguíneos neoformados, além de raras células inflamatórias mononucleadas. Muitos fibroblastos jovens e

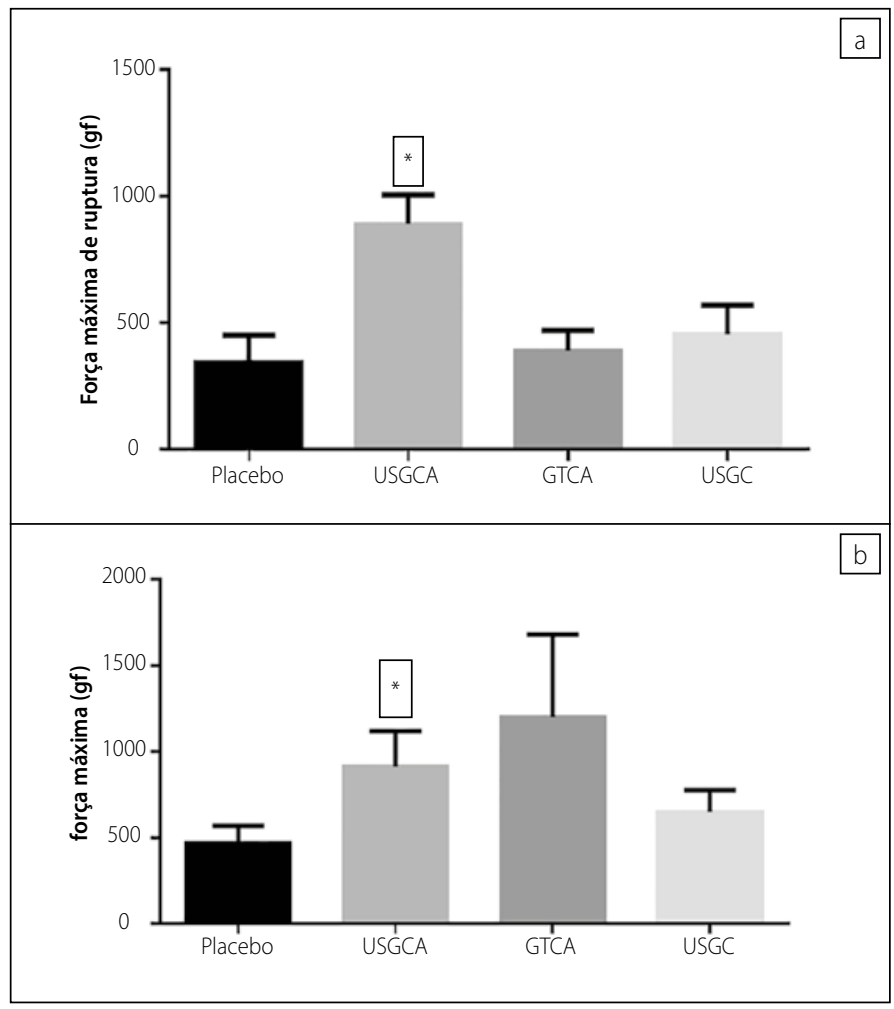

Figura 2. USGCA (Ultrassom com gel do caule); GTCA (Gel tópico do caule); USGC (Ultrassom com gel comum). a)Força máxima de ruptura após a indução da inflamação com colagenase no tendão do rato; b) Grupos de animais eutanasiados em sete e quatorze dias, respectivamente. Valores expressos em média \pm desvio padrão.

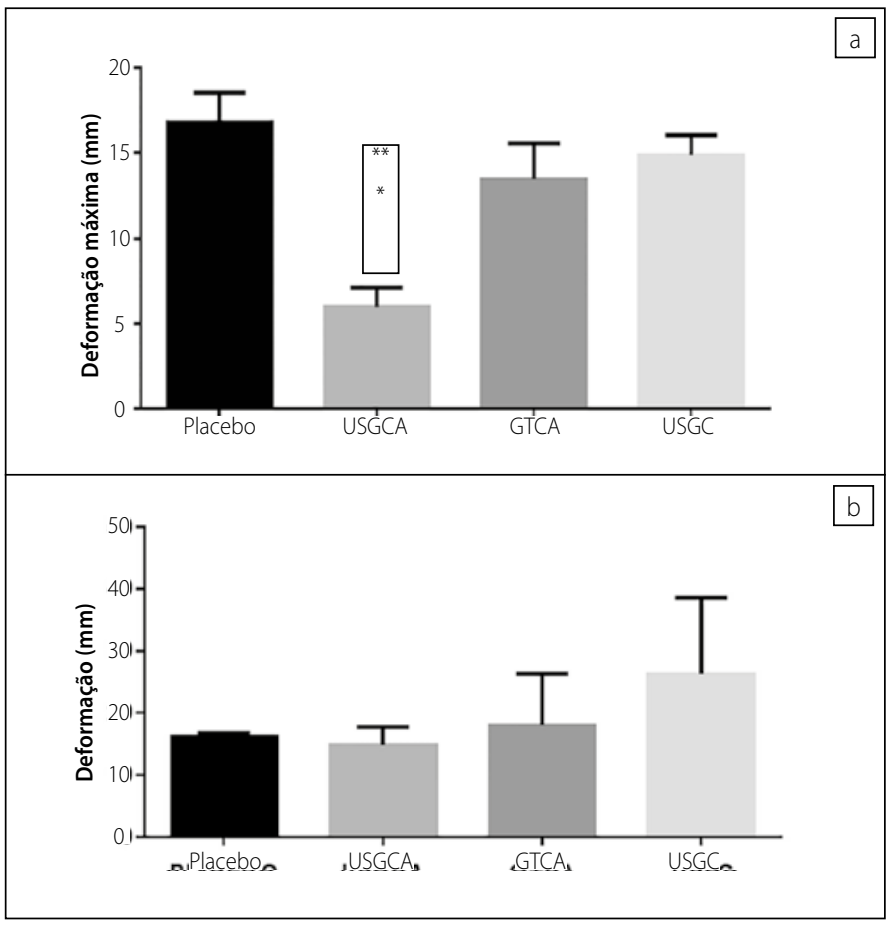

Figura 3. USGCA (Ultrassom com gel do caule); GTCA (Gel tópico do caule); USGC (Ultrassom com gel comum); a) Deformação máxima após a indução da inflamação com colagenase no tendão do rato; b) Grupos de animais eutanasiados em sete e quatorze dias, respectivamente. Valores expressos em média \pm desvio padrão. 
em atividade. A matriz extracelular mostrou-se mais frouxa e com reação fracamente positiva para o tricrômico de Masson (TM).

No Grupo USGCA (Figura 5E e 5F), os fibroblastos apresentaram-se de forma bastante organizada. A neoangiogênese se manteve intensa. Na matriz o padrão de coloração pelo tricrômico de Masson se assemelhava ao do tendão normal.

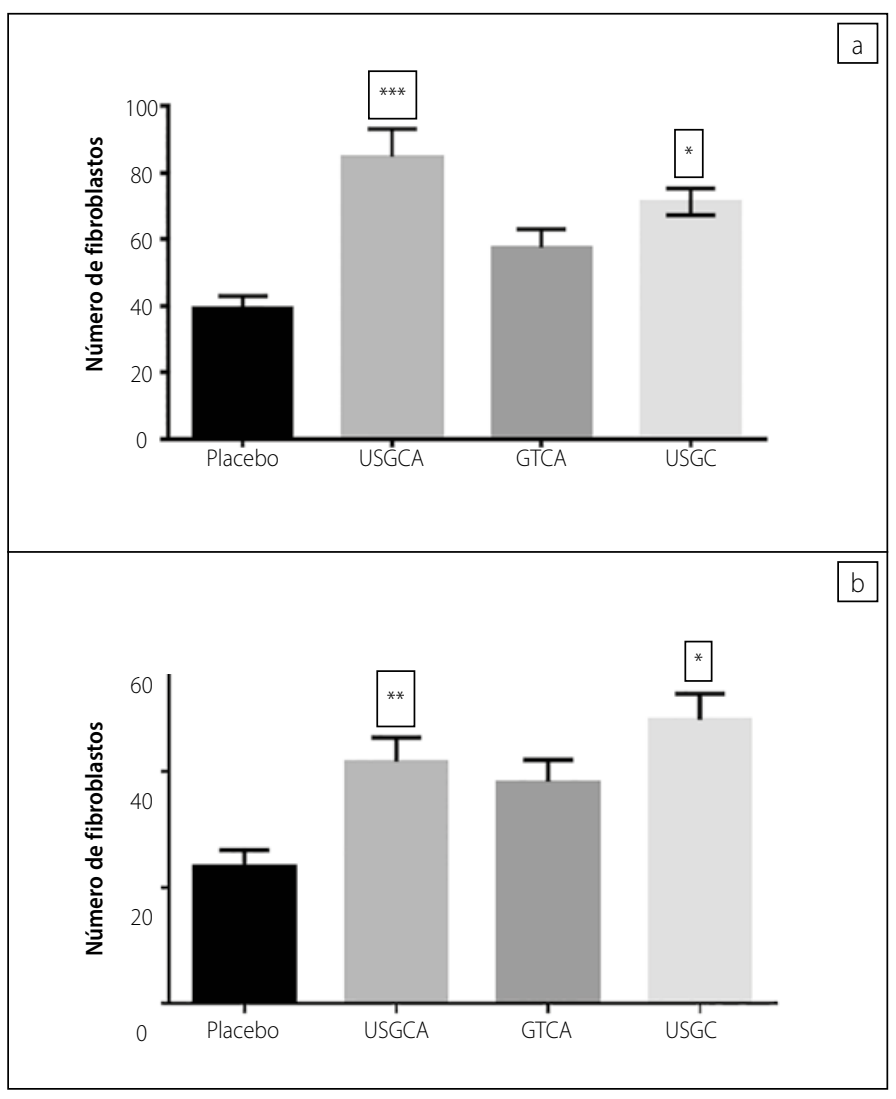

Figura 4. USGCA (Ultrassom com gel do caule); GTCA (Gel tópico do caule); USGC (Ultrassom com gel comum); a) Número de fibroblastos mensurados na avaliação microscópica após a indução da inflamação com colagenase no tendão do rato; b) Grupos de animais eutanasiados em sete e quatorze dias, respectivamente. Valores expressos em média \pm desvio padrão.

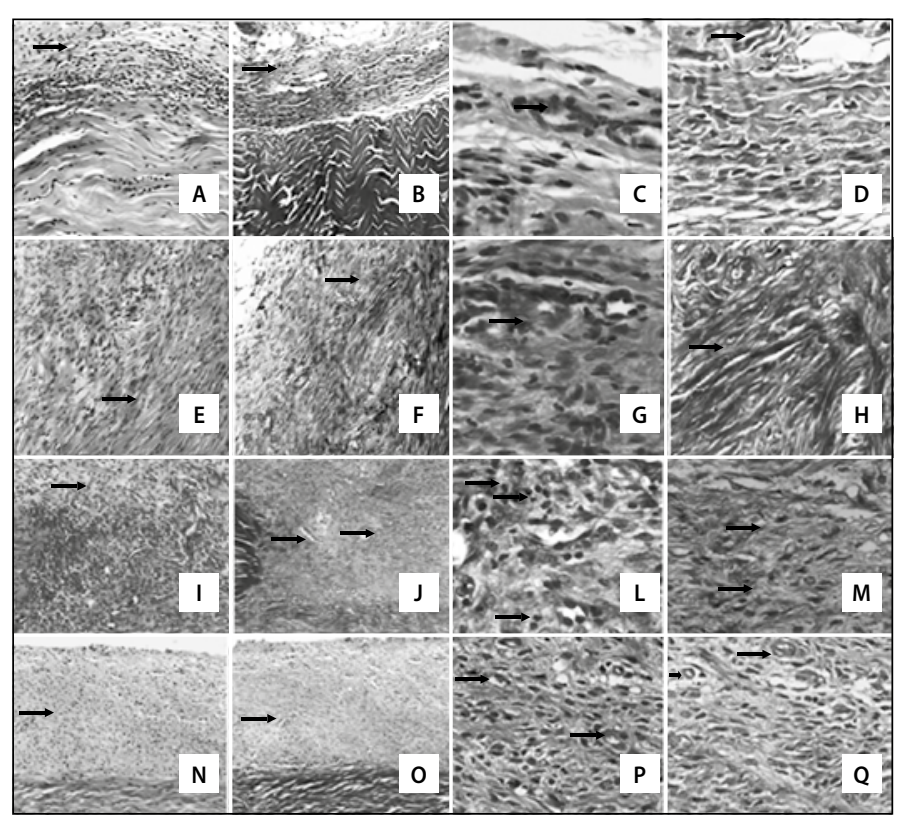

Figura 5. Aspectos histológicos 7 dias dos tendões dos animais: Grupo Placebo. A) (H.E. 100x); B) (TM, 100x); C) (H.E., 400x); D) (TM, 400x). Grupo USGCA: E-F) (H.E. 100x e TM, 100x); G-H) (H.E., 400x; TM, 400x). Grupo GTCA: I) (H.E., 100x); J) (TM, 100x); L) (H.E. 400x); M) (TM, 400x). Grupo USGC: N) (H.E., 100x); O) (TM, 100x); P) (H.E., 400x); Q) (TM, 400x).
No Grupo GTCA, (Figura 5l e 5J), foram encontradas numerosas células inflamatórias mononucleadas e neutrófilos, denotando persistência de reação inflamatória aguda e a matriz extracelular de aspecto fibrilar e frouxo.

No Grupo USGC (Figura 5L e 5M), comparado com o Grupo Placebo, o epitendão mostrou-se muito mais alargado e com número maior de fibroblastos, capilares sanguíneos e células inflamatórias mononucleadas.

Em 14 dias (Figura 6), as análises histológicas em laminas coradas com Hematoxilina-Eosina (HE) e tricômico de Masson (TM) mostraram no grupo Placebo (Figura 6A e 6B) houve redução expressiva das células fibroblásticas. Células inflamatórias mononucleadas foram muito raras. A matriz extracelular mostrou-se edemaciada, nas preparações coradas pelo tricrômico.

No Grupo USGCA (Figura 6E e 6F), o epitendão revelou-se ainda espessado e com celularidade alta, porém menos intensamente que o mesmo grupo com sete dias de experimento. Os fibrócitos encontravam-se em maior quantidade. Células inflamatórias mononucleadas não foram encontradas. A matriz extracelular mostra-se densa e com padrão de coloração semelhante ao do tendão.

No Grupo GTCA (Figura 6l e 6J), o epitendão revelou-se menos espessado e com menor número de células e a matriz extracelular, permeada por células adiposas, mostrou-se densa.

No Grupo USGC (Figura 6L e 6M), o epitendão revelou-se mais espessado e com maior número de células. As células são representas predominantemente por fibroblastos e fibrócitos dispostos em feixes paralelos ao tendão.

\section{DISCUSSÃO}

Observou-se que neste estudo o ultrassom com gel comum-USGC e o ultrassom com gel do caule-USGCA obtiveram menores médias quando comparados ao grupo placebo, indicando a redução co-substancial do edema presente no processo inflamatório inicial com esses tratamentos (Figura 1). Esses resultados mostram a superioridade da sonoforese com gel do caule (USGCA) em sete dias, quando comparado com os outros tratamentos. Dessa forma, os bons resultados com o gel do caule (USGCA) podem ser inferidos pela somatória ação do ultrassom pulsado na quebra da impedância da pele e na penetração do fitoterápico na capacidade de ação anti-inflamatória ${ }^{8,14,15}$.

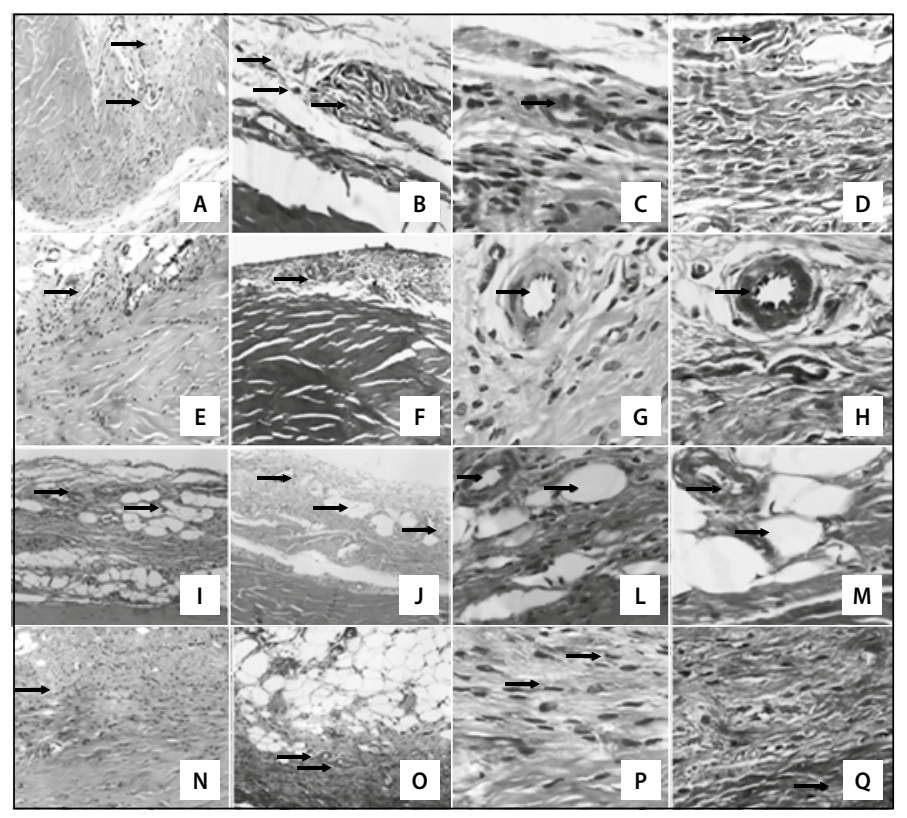

Figura 6. Aspectos histológicos 14 dias dos tendões dos animais: Grupo Placebo: A) (H.E. 100x); B) (TM, 100x); C) (H.E. 400x); D) (TM, $400 \mathrm{x})$. Grupo USGCA: E) (H.E, 100x); F) (TM, 100x); G) (HE. 400x); H) (TM, 400x). Grupo GTCA: I) H.E. 100x); J) (TM, 100x); L) (H.E. 400x); M) (TM,400x). Grupo USGC: N) (H.E., 100x); O) (TM, 100x); P) (H.E., 400x); Q) (TM, 400x). 
Os dados da sonoforese com fitoterápicos no tempo experimental de sete dias estavam concordantes quando comparados aos resultados de Maia-Filho et al. ${ }^{8}$, que observaram a ação da sonoforese com Aloe vera em edema induzido em patas de ratos.

Os efeitos benéficos da sonoforese do gel do caule da X. americana na diminuição do edema podem ser também justificados pela própria composição química da planta. Seu extrato contém flavonoides e catequinas que são inibidores da prostaglandinas e processos inflamatórios $^{16}$. As pesquisas ${ }^{17-20}$ demonstram e comprovam a atividade anti-inflamatória da $X$. americana confirmando de forma mais consistente os dados encontrados na ação da planta em sete dias pós-tratamento.

Os dados da força máxima se observa que o ultrassom isolado pulsado USGC, a sonoforese com gel do caule-USGCA e do gel do tópico do caule-GTCA tiveram maior resistência a tração e necessitaram de mais carga para romper totalmente sua nova estrutura tendínea quando comparado com o grupo placebo (Figura 2a).

No décimo quarto dia (Figura 2b) o gel tópico do caule- GTCA pelas médias se sobressaiu aos demais grupos quando comparado ao placebo. Os dados de aumento da força de ruptura no tendão encontrada na sonoforese com gel do caule (USGCA) estavam concordantes quando comparados a pesquisa de Fu et al..$^{21}$.

Esse incremento biomecânico de força máxima no ultrassom com gel do caule (USGCA) é atribuído ao fato de que o ultrassom ativa as células inflamatórias, resultando em debridamento do tendão e a produção de mediadores químicos, que levam a ativação dos fibroblastos. Isto leva ao acúmulo anterior de células endoteliais dos tecidos e a promoção da síntese de colágeno através da estimulação do fluxo de cálcio, alteração da permeabilidade da membrana ${ }^{22,23}$, depositando um colágeno mais forte e organizado ${ }^{22,23}$ e que percorre as fases de cicatrização de maneira mais rápida ${ }^{24}$.

A deformação máxima foi avaliada neste estudo no sétimo (Figura 3a) e décimo quarto dia (Figura 3b) de tratamento. Observa-se que nos sete primeiros dias houve uma redução da deformação no grupo sonoforese com gel do caule (USGCA) quando comparado com grupo ultrassom (UGC) e o placebo contrapondo-se ao aumento de força máxima de ruptura. Esse resultado é similar ao do experimento de Romano et al. ${ }^{25}$.

Deste fato podem-se aventar duas hipóteses: a que o incremento de colágeno no grupo sonoforese com gel do caule (USGCA) aconteceu, mas não houve a organização neste período das fibrilas ou que o percentual de elastina foi reduzido induzindo a perda da elasticidade e deformação precoce.

Segundo Aquino et al. ${ }^{26}$, o colágeno confere resistência e força tênsil, a elastina confere elasticidade e a água à capacidade de deformação elástica ao tendão, o colágeno possibilita ao tecido resistir a forças mecânicas e deformações e a elastina auxilia na recuperação da deformação. De forma que a redução do percentual elástico ou não reorganização fibrilar podem culminar na redução da deformação.
A contagem de fibroblastos em sete dias (Figura 4a) mostrou que o ultrassom com gel comum-USGC e ultrassom com gel do caule-USGCA, apresentaram o maior incremento quando comparado com os outros grupos tratados. Aos quatorze dias de tratamento (Figura 4b), houve uma redução significativa nos grupos ultrassom com gel comum-USGC e ultrassom com gel do caule-USGCA quando comparados ao grupo placebo. Estes dados coincidem com os de Demir et al.. ${ }^{27}$.

\section{Análise histológica}

Os achados histológicos encontrados no grupo de ultrassom com gel comum (USGC) em sete dias (Figura 5L e M), foram corroborados pela análise de Moura-Junior et al. ${ }^{6}$ e Cunha et al. ${ }^{28}$. Na sua análise histológica foi encontrado epitendão e o endotendão alargados com aumento do número de tenoblasto com uma progressão maior de organização, dispondo-se em feixes mais definidos, sobretudo em áreas mais próximas aos feixes preexistentes e da matriz extracelular, células inflamatórias mononucleada em menor número. Demonstrou resultado superior ao processo de cicatrização comparado com Moura-Júnior et al. ${ }^{6}$.

A análise histológica da sonoforese do caule (USGCA) em sete dias (Figura $5 \mathrm{~F} \mathrm{e} \mathrm{G}$ ) caracterizou-se pela presença de numerosos fibroblastos e vasos sanguíneos neoformados, indicando processo inflamatório agudo-crônico. Em quatorze dias (Figura 6F e G), a análise histológica reforça a redução da inflamação no grupo sonoforese com gel do caule (USGCA), pois a matriz extracelular teve uma matriz densa e organizada contrapondo-se a uma matriz edemaciada do placebo e frouxa do grupo ultrassom com gel comum (USGC).

A organização histológica do ultrassom com gel do caule (USGCA) foi similar à observada no experimento de Maia-Filho et al. ${ }^{8}$, denotando assim o potencial cicatricial do gel da $X$. americana. No grupo sonoforese com gel tópico do caule (GTCA) há a persistência de reação inflamatória aguda tanto nos sete quanto nos quatorze dias.

\section{CONCLUSÃO}

No presente estudo, a sonoforese com gel das cascas caule de $X$. americana foi mais efetivo na redução da resposta inflamatória crônica á medida que, em sete e quatorze dias, reduziu o nível de edema, aumentou a força máxima de ruptura e reduziu a deformação inferindo sobre as propriedades biomecânicas do tendão.

\section{AGRADECIMENTOS}

À Universidade Estadual do Piauí; à Faculdade Santo Agostinho; à Universidade do Vale do Paraíba e à Universidade Federal de Alagoas.

$\overline{\text { Todos os autores declararam não haver qualquer potencial conflito }}$ de interesses referente a este artigo.

CONTRIBUIÇÕES DOS AUTORES: Cada autor contribuiu individual e significativamente para o desenvolvimento do manuscrito. SSL (0000-0001-5993-974X)* participou substancialmente na concepção do trabalho. JFS (0000-0002-7117-8784)*, AEGS (0000-0003-3989-9028)* e MBJ (0000-0002-3535-6512)* participaram no desenho do trabalho, aquisição, análise e interpretação dos dados e redação do artigo. AMMF (0000-0001-6184-8003)* contribuiu no manuseio dos animais, análise estatística dos dados e interpretação dos achados. RBS (0000-0001-5503-7116)*, DMM (0000-0003-4504-4130)* e RCA (0000-0001-5503-7116)* contribuíram na concepção do trabalho e análise dos dados e redação. VTU (0000-0001-8080-6335)* contribuiu na coleta da planta, produção do extrato, produção do gel e redação do artigo. SSL e VTU participaram da revisão crítica do conteúdo e aprovação final do manuscrito. Todos os autores contribuíram com o conceito intelectual do estudo. ${ }^{*}$ ORCID (Open Researcher and Contributor ID).

\section{REFERÊNCIAS}

1. Garcia, VMD, Mazzoni, CF, Corrêa, DF, Pimenta, RU. Análise do perfil do paciente portador de doença osteomuscular relacionada ao trabalho (DORT) e usuário do serviço de saúde do trabalhador do SUS em Belo Horizonte. Rev Bras Fisioter. 2004;8(3):273-8.

2. van Sterkenburg MN, van Dijk CN. Mid-portion Achilles tendinopathy: why painful? An evidence-based philosophy. Knee Surg Sports Traumatol Arthrosc. 2011;19(8):1367-75.

3. Müller SA, Todorov, A, Heisterbach, PE, Martin I, Majewski, M. Tendon healing: an overview of physiology, biology, and pathology of tendon healing and systematic review of state of the art in tendon bioengineering Knee Surg Sports Traumatol Arthrosc. 2015;23(7):2097-105.

4. Allahverdi, A, Sharifi, D, Takhtfooladi, MA, Hesaraki, S, Khansari, M, Dorbeh, SS. Evaluation of low-level lase therapy, platelet-rich plasma, and their combination on the healing of Achilles endon in rabbits. Lasers Med Sci. 2015;30(4):1305-13.

5. de Mattos LH1, Álvarez LE, Yamada AL, Hussni CA, Rodrigues CA, Watanabe MJ, et al. Effect of phototherapy 
with light-emitting diodes ( $890 \mathrm{~nm}$ ) on tendon repair: an experimental model in sheep. Lasers Med Sci. 2015;30(1):193-201.

6. Moura-Júnior MJ, Arisawa EÂA, Martin AA, de Carvalho JP, da Silva JM, Silva JF, et al. Effects of low-power LED and therapeutic ultrasound in the tissue healing and inflammation in a tendinitis experimental model in rats. Lasers Med Sci. 2014;29(1):301-11.

7. Xavier M, de Souza RA, Pires VA, Santos AP, Aimbire F, Silva JA Jr, et al. Low-level light-emitting diode therapy increases mRNA expressions of IL-10 and type I and III collagens on Achilles tendinitis in rats. Lasers Med Sci. 2014;29(1):85-90.

8. Maia Filho AL1, Villaverde AB, Munin E, Aimbire F, Albertini R. Comparative study of the topical application of Aloe vera gel, therapeutic ultrasound and phonophoresis on the tissue repair in collagenase-induced rat tendinitis. Ultrasound Med Biol. 2010;36(10):1682-90

9. Contreras JM, Bourguignon JJ. The Practice of Medicinal Chemistry. 2nd ed. New York: Academic Press, 2003.

10. Peters CA, Sgrott RAG, Peters RR, Moterle D, Madeira F, Emer AA, et al. Production of Wilbrandia ebracteata extract standardized in flavonoids and dihydrocurcubitacin and assessment of its topical anti-inflammatory activity. Industrial Crops an Products. 2015;69:123-8.

11. Brasileiro MT, Egito AA, Lima JR, Randau, KP, Pereira GC, Rolim-Neto PJ. Ximenia americana L.: botânica, química e farmacologia no interesse da tecnologia farmacêutica. Rev Bras Farm. 2008;89(2):164-7.

12. James $D B$, Abu EA, Wurochekke AU, Orji GN. Phytochemical and antimicrobial investigation of the aqueous and methanolic extracts of Ximenia americana. J Med Sci, 2007;7(2):284-8.

13. Morais, SM, Dantas, JDP, Da Silva, ARA, Magalhães, EF. Plantas medicinais usadas pelos índios Tapebas do Ceará. Rev. Bras. Farmacogn. 2005;15(2):169-77.

14. Martins M, Maia-Filho ALM, Costa CLS, Coelho NPM, Costa MS, Carvalho RA. Ação anti-inflamatória da fração lipídica do Ovis aires associado ao ultrassom terapêutico em modelo experimental em tendinite em ratos (Rattus norveficus). Rev Bras Fisioter. 2011;15(4):297-302.

15. Onifade AO, Ouedraogo M, Ouedraogo M, Zongo FE, Kafando E, Lompo M, et al. Acute toxicity and anti-inflammatory activity of aqueous ethanol extract of root bark of Ximenia americana L. (Olacaceae). African J Pharm Pharmacol. 2011 [acesso em 2015 jul 15]; 5(7):806-11. Disponivel em http://www.academicjournals. org/journal/AJPP/article-full-text-pdf/052A26028156.
16. Le NHT, Malterud KE, Diallo D, Paulsen BS, Nergård CS, Wangensteen H. Bioactive polyphenols in Ximenia americana and the traditional use among Malian healers. J. Ethnopharmacol. 2012;139(3):858-62.

17. Calixto, JB. Twenty-five years of research on medicinal plants in Latin America: a personal view. J Ethnopharmacol. 2005;100(1-2):131-4

18. Calixto JB, Campos MM, Otuki MF, Santos AR. Anti-inflammatory compounds of plant origin. Part II. Modulation of pro-inflammatory cytokines, chemokines and adhesion molecules. Plant Med, 2004;70(2):93-03.

19. Ogunleye DS, Ibitoye SF. Studies of antimicrobial activity and chemical constituents of Ximenia americana. Trop J Pharm Res, 2003 [acesso em 2015 ago 20]; 2(2):239-41. Disponivel em http://www.ajol.info/index. php/tjpr/article/view/14606).

20. Ojewole JAO, Analgesic and antiinflammatory effects of mollic acid glucoside, a 1a-hydroxycycloartenoid saponin extractive from Combretum molle R. Br. ex G. Don (Combretaceae) leaf. Phytother. Res. 2008;22(1):30-5

21. Fu SC, Shum WT, Hung LK, Wong MWN, Qin L, Chan KM. Low-intensity pulsed ultrasound on tendon healing: a study of the effect of treatment duration and treatment initiation. Am J Sports Med. 2008; 36(9):1742-9

22. Baker KG, Robertson VJ, Duck FA. A review of therapeutic ultrasound: biophysical effects. Phys Ther. 2001;81(7):1351-8.

23. Lai J, Pittelkow MR. Physiological effects of ultrasound mist on fibroblasts. Int J Dermatol. 2007;46(6):587-93.

24. Enwemeka CS. Functional loading augments the initial tensile strength and energy absorption capacity of regenerating rabbit Achilles tendon. Am J Phys Med Rehabil. 1992;71(1):31-8.

25. Romano CVG, Barbieri CH, Mazzer N, Volpon JB, Shimano AC, Roncaglia FB. O ultra-som terapêutico não aumentou as propriedades mecânicas de tendões flexores após reparo. Acta Ortop Bras. 2010;18(1):10-4

26. Aquino, CF, Viana SO, Fonseca ST. Comportamento biomecânico e resposta dos tecidos biológicos ao estresse e à imobilização. Fisioter Mov. 2005;18(2):35-43.

27. Demir H, Menku P, Kirnap M, Calis M, Ikizceli I. Comparison of the effects of laser, ultrasound, and combined later and ultrasound treatments in experimental tendon healing. Laser Surg Med. 2004;35(1):84-9.

28. da Cunha A, Parizotto NA, Vidal BC. The effect of therapeutic ultrasound on repair of the Achilles tendon (tendo calcaneus) of the rat. Ultrasound Med Biol. 2001;27(12):1691-6. 